\title{
DESTINATION SOUTH AFRICA: ANALYSIS OF DESTINATION AWARENESS AND IMAGE BY INTERNATIONAL VISITORS
}

\author{
René HAARHOFF \\ Central University of Technology, Free State, Faculty of Management Sciences, \\ Department of Tourism and Event Management, Hotel School, Room 20, \\ 20 President Brand Street, Bloemfontein, 930o, e-mail: rnel@cut.ac.za

\section{Bianca DE KLERK*} \\ Central University of Technology, Free State, Faculty of Management Sciences, \\ Department of Tourism and Event Management, Hotel School, Room 116B, \\ 20 President Brand Street, Bloemfontein, 930o, e-mail: meyerb@cut.ac.za
}

\begin{abstract}
Citation: Haarhoff, R. \& De Klerk, B. (2019). DESTINATION SOUTH AFRICA: ANALYSIS OF DESTINATION AWARENESS AND IMAGE BY INTERNATIONAL VISITORS. GeoJournal of Tourism and Geosites, 24(1), 201-211. https://doi.org/10.30892/gtg.24116-353
\end{abstract}

\begin{abstract}
International tourism is vital to South Africa's economy and tourism industry. It accounts for $48 \%$ of the country's tourism volume and $3 \%$ of GDP. It is important to establish the image that international visitors have of South Africa to safeguard the performance efficacy of the country's tourism industry. This study shows the efforts that South Africa have made to build a Nation Brand and describes the impact it's had on the perceptions of international visitors. The study population was international visitors to South Africa. Questionnaires were used to interview departing passengers at OR Tambo International Airport. Results indicated that the overall attractiveness of South Africa was positive. A majority indicated that they will return to South Africa.
\end{abstract}

Key words: branding, image, international tourism, international visitors

\section{INTRODUCTION}

Tourism is a global phenomenon. It is the world's largest and fastest-growing industry and is a major economic, environmental and sociocultural dynamic force. In South Africa, tourism is vitally important and a key driver of the economy. During 2016, tourism contributed 9.3\% to the South African gross domestic product (GDP) and supported approximately 1.5 million jobs. Tourism contributed US $\$ 4.74$ billion of total investment and generated US $\$ 8.81$ billion in visitor exports in 2016 (World Travel \& Tourism Council, 2017). This makes the South African tourism industry a larger contributor to the economy than agriculture (Statistics South Africa, 2018). International tourism is important to the South African tourism industry as it accounts for $48 \%$ of the

\footnotetext{
* Corresponding author
} 
country's total tourism volume; $87 \%$ of total tourism expenditure and about $3 \%$ of GDP (South African Tourism, 2017). During this period, international visitors spent approximately R20.0 billion on leisure, accommodation and food and mostly originated from Africa and Europe. Given the importance of the international market to the South African tourism industry, it is important to establish the image that South Africa depicts to international visitors. This is necessary to ensure the effective performance of the tourism industry in South Africa. Before this can be established, it is important to know how destination image is formed and the factors that influence image formation.

\section{Destination image, branding and positioning}

Destination image is defined as a tourist's mental picture of an offering while associating symbolic meanings with certain features of the destination. A clear and powerful image enables a destination to position itself in such a way that it will appeal to the needs and wants of its identified tourist market (Manhas et al., 2016). Destination image is formed by attribute-based and holistic components. Both contain functional and psychological dimensions (Schmallegger \& Carson, 2009). Functional attributes include characteristics of the destination such as climate, scenery and attractions. Psychological attributes depict the tourist's interpretation and appraisal of the destination characteristics such as the friendliness of locals and quality of products and services. Holistic components include the mental images that visitors have of the physical characteristics of the destination and the mood and atmosphere that they create (Schmallegger \& Carson, 2009). Factors that influence the formation of destination image comes from primary and secondary information sources and personal factors related to the tourist. Primary information sources are derived from information that visitors gain from a destination due to previous visits and the intensity of their visit. Secondary information is gained from organic, induced and autonomous sources. These are acquired before experiencing the destination (Beerli \& Martin, 2004). Organic information is gained from friends and family that have visited the destination previously. Induced information is required from advertising in the mass media.

Autonomous information comes from sources such as documentaries, films or television programs about the destination (Gartner, 1994). Personal factors, also called internal factors, are formed by the projected image of the destination and the tourist's own needs, motivation, prior knowledge and preferences. Visitors' create their own mental picture of the destination that will then produce their personal perceived images (Bramwell \& Rawding, 1996). Destination image is a multi-dimensional concept that is influenced by cognitive, distinctive and emotional images. Together these influence the behaviour of visitors (Maumbe \& Van Wyk, 2012). Destination image is very closely intertwined with destination positioning and destination branding. The interaction between these concepts are known as the positioning - image - branding (PIB) approach (Morrison, 2013). Destination positioning is the way a destination makes itself different from competing destinations and destination branding is the identity that is given to a destination. A destination's brand can also be referred to as its competitive identity (Morrison, 2013). Destination branding is a marketing strategy that support, identify, differentiate and communicate the unique features of a destination and aims to strengthen the emotional connection that visitors have with that destination. This is done to create and sustain a positive destination image amongst visitors. It also impacts on decisions for future destination positioning (Martins, 2015). In general, destination branding creates a series of quality images of a destination that visitors should desire before consumption resulting in positive word-of-mouth after consumption (Manhas et al., 2016).

An aspect of destination image and branding where there seem to be a scarcity in research involves the relationship between destination development and its brand image. 
A definition that best describe destination development refers to "the systematic use of scientific and technical knowledge to meet specific objectives or requirements." (Business Dictionary, 2018). This refers to the three-step system that may be used to develop a destination: firstly, establish the tourism resources available at the destination; secondly, identify the type of visitors to attract; and thirdly, find ways to reach these visitors to meet specific requirements (Clarke \& Godfrey, 2000). Developers and marketers should ensure that destination brand image is well-thought-out during these three steps. During step one destination image should be determined followed by the identification of a destination brand image that will match the type of tourist that the destination wishes to attract. Finally, step three involves finding the best way to use destination brand image to satisfy visitors whilst generating positive word-of-mouth and revisits (Manhas et al., 2016). Furthermore, to develop a successful destination image brand, the destination's infrastructure and tourism facilities should be developed and improved. Moreover, investment and workforce development, crucial for destination development, further supports destination image. Therefore, marketers and developers should promote their destinations to create an image that attracts visitors. When a variety of information sources are used to advertise a destination it ultimately leads to a positively shaped destination image (Baloglu \& McCleary, 1999).

\section{Destination South Africa}

This theoretical foundation of destination image, branding and positioning provides the perfect backdrop for examining the image that destination South Africa is striving towards as well as its main international source markets and competitors. This type of information could enlighten destination marketing organisations (DMOs), such as South African Tourism (SAT), and provide them with reasons why international visitors have a certain image of South Africa and how the potential gaps between established and perceived image of South Africa can be overcome. The public entity, Brand South Africa, is commissioned by the South African government to project a positive image of the country both continentally and internationally. Their main purpose is to encourage local and foreign investment, tourism and trade through the promotion of Brand South Africa (Brand South Africa Trust, 2018). Their idea of "Nation Brand" is based on the concept that the reputation of a nation is constructed on six elements - investment, governance, people, culture, tourism and exports. This is known as the Nation Brand Hexagon (Brand South Africa Trust, 2018). They have developed the catchphrase 'South Africa, Inspiring New Ways' that refers to the people of South Africa and how citizens, businesses, universities, civil society and government institutions can improve the country's global attractiveness and competitiveness (Brand South Africa Trust, 2018). Hence, the reasoning behind their brand strategy for South Africa that destination branding is a collective national effort that will make South Africa globally admired.

South African Tourism (SAT), the tourism marketing division of the South African government, has the task to promote South Africa both domestically and internationally. Their marketing strategy is to promote South Africa as a year-round tourist destination. Like Brand South Africa, they aim to establish an image of the country that signifies the people of South Africa when stating: '. . . . . you will not only visit the country but meet her people and her places' (South African Tourism, 2018). Their focus is to move away from South Africa's traditional set of attributes (wildlife, heritage, culture and adventure) towards creating an emotional connection with visitors by showcasing our nation's way of life where visitors can engage with South Africans on a personal level (South African Tourism, 2018). Looking from an international perspective, three of South Africa's major tourist destinations include Cape Town, Durban and Johannesburg. Each of these cities have successfully established their own unique brand image. 
Cape Town is known for its scenic beauty, celebrity beaches, Table Mountain, whale-watching, world-class shopping, nightlife, food, wine as well as its laid-back atmosphere. Durban positions itself as a world city and caters for those with fun and sun on their minds. Its known as South Africa's sunshine city that has something for the entire family including golden beaches and some of the best surfing spots in the world. Johannesburg is branded as the 'City of Gold' and it is said that South Africa's 'pulsating heartbeat' can be felt in Johannesburg. It is known as a city with endless opportunities for shopping, entertainment, freedom tours and dining out (South Africa, 2018). These cities play a critical role in shaping the fate of the South Africa and the Nation Brand. There is a dynamic interrelationship between the global image, brand and positioning of a city and that of Nation Brand. The global image, brand and positioning of the South African Nation Brand is directly influenced by the dynamics of Cape Town, Durban and Johannesburg (All Africa, 2018). Research done by Brand South Africa found that the reputation, visibility and successes of Cape Town, Durban and Johannesburg directly impacts on the profile and reputation of the South African Nation Brand (All Africa, 2018).

\section{South Africa's main source markets}

An important aspect in the formation of a country's image and brand is to know where the greater part of its international market comes from as well as its competing markets. South Africa receives international visitor arrivals from all regions in the world but have managed to identify source markets in some of these regions. Visitor arrivals from Asia is predominantly driven by China despite for their arrivals that declined by 16.3\%. The top three markets from Africa includes Zimbabwe, Lesotho and Mozambique. The main purpose for their visit were to visit friends and relatives (VFR) or to shop. Their visits had large economic impact on road transport and the retail sector. Unfortunately not much was spend in the traditional tourism sectors (South African Tourism, 2018).

Central and South America continues to grow with increased interest from Argentina and Brazil (South African Tourism, 2018). Visitors from Brazil perceive South Africa as an attractive leisure destination. Their visits increased from $71 \%$ in 2014 to $78 \%$ in 2017 (South African Tourism, 2018). Looking at the overall number of inbound visitors per region, 2017 statistics show that the majority originated from Africa (74.8\%) followed by Europe (13.8\%), North America (4.6\%) and Asia (3.3\%) (South African Market Insights, 2017). The nature of the visits from Africa are to visit friends and relatives (VFR). Europe, North America and Asia predominantly visit South Africa for holiday and leisure purposes (South African Tourism, 2018). Most of their money is spend on shopping, food and drinks (South African Tourism, 2018). A majority of this income is generated by Europe (R8.5 billion) followed by Africa (R8.1 billion). Activities that these visitors partake in whilst in South Africa range from shopping (Africa), eating out (Europe, Asia and North America. During the third quarter of 2017, Gauteng, Limpopo and Mpumalanga were the top three provincial destinations among international visitors. The main source markets for these provinces included the USA, UK and Germany (South African Tourism, 2017). In terms of South Africa's main source markets, Brazil, India and China show the biggest increase in arrivals.

\section{South Africa's competitive markets}

Visitors are attracted to many places in the world, and many countries compete with South Africa as they offer similar experiences such as beach, nature, wildlife, history, culture and adventure (Came, 2015). The impact of globalisation on tourism resulted in visitors being more knowledgeable having a better awareness of destinations around the world. The competition to attract visitors have become severe considering the number of places on hand for travel. African countries in direct competition with South Africa include Kenya, Rwanda and Uganda (East Africa). They are growing at a 
fast rate and are becoming attractive tourist destinations (Schoeman, 2016). On an international front, South Africa benchmarks its tourism performance against Australia and Thailand (South African Tourism, 2017). It is essential that South Africa becomes more competitive. Competitiveness is important because of three main reasons: visitors are becoming more educated and informed; visitor needs, and trends are changing; and more destinations compete for the same markets (Saayman, 2015). Although factors such as proximity and price affect which destinations visitors visit, competitors are mainly determined by what experiences are on offer.

\section{MATERIALS AND METHODS}

The population of this study was international visitors to South Africa that have completed their journey. The questionnaires were completed in the departure terminal of Johannesburg's Oliver Tambo International Airport. Different time slots and different days of the week were used for completion of the questionnaires. Departing passengers were selected randomly in the international departure lounge. The respondents are all international visitors who have already used South Africa's tourism products and were able to base their answers, responses and perceptions on their recent visit to South Africa.

The respondents were chosen randomly, giving each member of the population an equal chance of being chosen, in the international departure terminal of Oliver Tambo International Airport. Only foreigners, not permanently residing in South Africa, were questioned by means of a personal interview. The questionnaire covered a wide range of variables and contained both open-ended and closed-ended questions that were mainly divided into the following categories: the profile of the visitor, air transportation, accommodation, attractions and overall perception of South Africa. The questionnaire's validity, consistency and clarity of questions were tested by providing a sample questionnaire to a reputable local travel management company for their inputs and recommendations after which the necessary changes were made to eliminate possible problem areas and any ambiguity in the questionnaire. A total of 305 usable questionnaires were completed. Data was cleaned, captured and analysed using Microsoft Excel and R. Relationships between categorical variables are explored using chi-square analysis.

\section{RESULTS DISCUSSIONS}

Of the 305 questionnaires completed, 279 respondents indicated their gender, with $65.4 \%$ being male. The median age of the respondent was 35 . When asked to indicate whether they had visited SA before, only a small minority $(n=27,8.9 \%)$ were visiting South Africa for the first time, leaving $n=277$ who had visited South Africa before. It was thus evident that most respondents had visited SA before, and further that most were frequent previous visitors: Those who had visited South Africa six or more times constituted $40.3 \%$ of the entire sample. On the basis of this, the sample was split into three groups for certain later analyses, viz. those who were entirely new to South Africa (those who had never been to SA before), those who had been introduced to South Africa (those who had been to SA one to five times previously), and those who were very familiar with South Africa (those who had been to SA six or more times previously). When asked to indicate their reasons for visiting South Africa, the respondents mostly indicated that they had come for business $(n=135,44.3 \%)$ or holidays $(n=94,30.8 \%)$, with a further $44(14.4 \%)$ indicating that the purpose was to visit family and/or friends (Table 1). The 42 "other" responses were specified as shown in Table 2, where it was evident that educational reasons (school, university, other training) also presented as a common reason for visiting the country. Emerging markets such as medical tourism, wildlife tourism and religious tourism were also indicated (Table 2). 
Table 1. Reasons for visiting South Africa

\begin{tabular}{|l|c|c|}
\hline Reason for visiting SA & N & $\%$ \\
\hline Business & 135 & $44.26 \%$ \\
\hline Holiday & 94 & $30.82 \%$ \\
\hline Visit & 44 & $14.43 \%$ \\
\hline Complimentary & 1 & $0.33 \%$ \\
\hline Sport & 4 & $1.31 \%$ \\
\hline Other & 42 & $13.77 \%$ \\
\hline
\end{tabular}

Table 2. Other reasons for visiting South Africa

\begin{tabular}{|l|c|c|}
\hline Other reason for visiting SA & $\mathrm{N}$ & $\%$ \\
\hline Education \& Training & 17 & $40.48 \%$ \\
\hline Conferences \& Workshops & 7 & $16.67 \%$ \\
\hline Transit & 4 & $9.52 \%$ \\
\hline Work related & 3 & $7.14 \%$ \\
\hline Church & 2 & $4.76 \%$ \\
\hline Bird watching & 2 & $4.76 \%$ \\
\hline Overnight stay & 1 & $2.38 \%$ \\
\hline Official missions & 1 & $2.38 \%$ \\
\hline DJ/Entertainment & 1 & $2.38 \%$ \\
\hline Medical & 1 & $2.38 \%$ \\
\hline Unspecified & 3 & $7.14 \%$ \\
\hline
\end{tabular}

In order to understand whether these reasons for visiting SA had any bearing on the image and/or perception of SA as a tourist destination, these various motives were grouped as being either formal (e.g., business, education), recreational (e.g., holiday, visit), or mixed (both formal and informal-since sport was not clear as being an athlete or a spectator, it was also included in mixed). When asked to summarise their feelings about South Africa as a tourist venue by giving a rating of the overall attractiveness of South Africa, the rating was again overwhelmingly positive, with four fifths (80.7\%) giving a positive rating, and almost a fifth (18.2\%) giving a neutral rating (Figure 1).

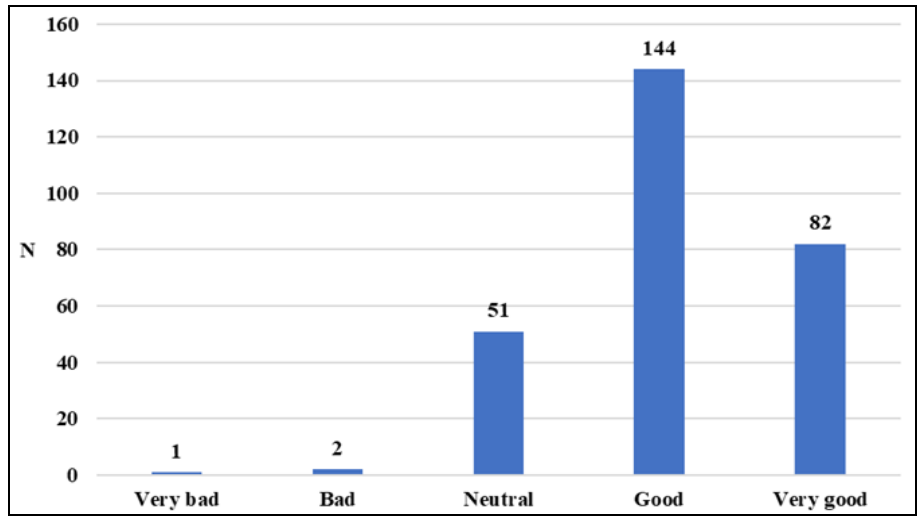

Figure 1. Attribute rating: Overall attractiveness

The respondents were also asked to rate three of South Africa's major tourist destinations namely Cape Town, Johannesburg, and Durban. These are the three cities in South Africa which draw the largest number of international visitors annually. Between April 2017 and March 2018, the following international passenger arrival statistics were recorded at OR Tambo, King Shaka and Cape Town International Airports: 4578180 at OR Tambo; 1110454 at Cape Town International; and 167514 at King Shaka (Airports Company South Africa, 2018). A comparison of the three cities reveals that Cape Town has by far the best perception amongst the respondents, Durban in KwaZulu-Natal, also a seaside city was rated second best whilst Johannesburg in Gauteng received the lowest rating. Cape Town is one of the top destinations in the world and has received various awards over the last few years. The most recent include Cape Town being named one of the top 10 surf cities in the world by Surfer as well as the number one city in Africa for business tourism events by the International Congress and Convention Association (Cape Town 
Tourism, 2018). It should be kept in mind, though, that the overall rating for each city was overwhelmingly positive which also correlates with the results in figure 1 where the destination overall received a favourable rating. Cape Town received very positive ratings, with $86.9 \%$ of the respondents giving it a positive rating. By contrast, Johannesburg was rated less favourably, although most of its ratings were still positive, with $77.4 \%$, more than three quarters of the respondents, giving it a positive rating, and only $4.8 \%$ of the respondents giving it a negative rating. Durban had very similar ratings to Johannesburg, with $78.5 \%$ of respondents giving it a positive rating, and $3.5 \%$ a negative rating, although the proportion of "Very good" responses was considerably higher for Durban (Figure 2).

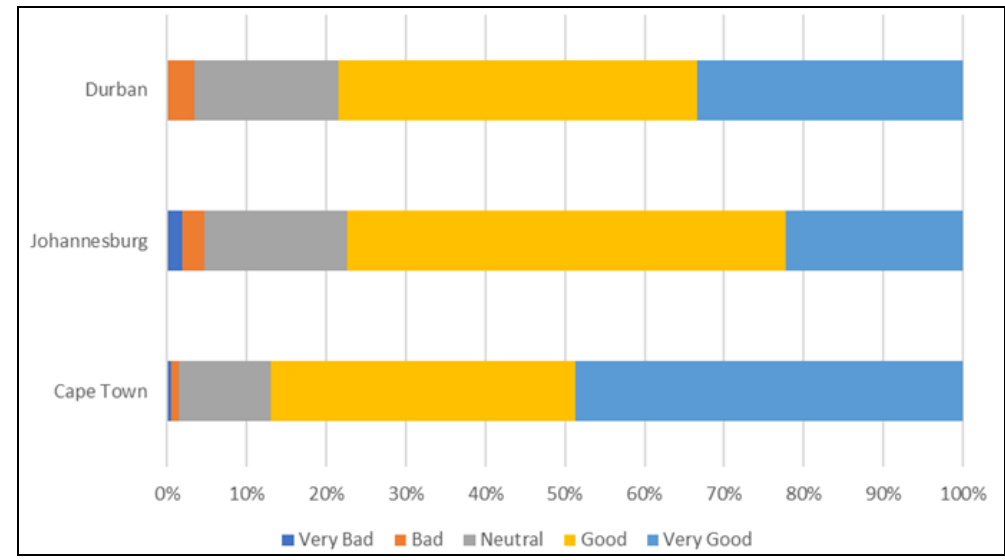

Figure 2. City ratings and tourist venues

The research furthermore aimed to determine the price sensitivity of respondents and whether the weaker Rand, which in general makes South Africa a more affordable destination to most visitors, had any direct influence on the respondent's choice to visit SA. Respondents were thus asked to indicate whether price was a main consideration in choosing South Africa as a destination. Results reflect that a third ( $\mathrm{n}=100 ; 33.9 \%)$ of respondents indicated that price was the main consideration for visiting SA. All respondents were then asked to indicate whether they had considered an alternative destination for their visit to SA. Only 233 respondents answered this question, but of those, almost two thirds (64.8\%, but only $49.5 \%$ of the total sample) indicated that they had not considered an alternative destination. It is thus clear that South Africa should guard against becoming an expensive destination as the cost of air transportation, in many instances the largest expense to the visitor, is already contributing towards the travel budget of the visitor. Those respondents who did indicate that they had considered an alternative destination were then asked to identify the destinations which they had considered as alternatives to South Africa. These could, thus, in a sense be "competitors" to SA in the tourist market. The list of alternative destinations from all over the world were quite eclectic but from the results it was clear that the alternative destinations that were considered that received the highest score were mostly located in and/or around South Africa such as Dubai (9.3\%), Mauritius (5.4\%), Namibia (4.7\%), and Zimbabwe (3.9\%).

Despite many respondents having considered alternative destinations to South Africa, the encouraging news is that when asked whether they would visit SA again results indicated an overwhelming positive response where only seven respondents said no, and one respondent said maybe. Some of the reasons listed for not visiting South Africa again by the 7 respondents were:

- $\quad$ I prefer to get to know other places 


\section{- $\quad$ One trip only \\ - The embassy official is so unfriendly in giving visas \\ - $\quad$ Three times enough \\ - Unsafe, corrupt and extremely crime prone \\ - Unsafe, no law and order, theft \& corruption is rampant}

Sadly, three of the reasons listed above could be considered "preventable" in that they were extrinsic motivators related to the country. Crime and corruption was mentioned by two of these respondents, which is disheartening. The response about the embassy officials especially should be concerning. It may be reasoned that only one respondent out of 305 put off by unfriendly staff is a very small percentage, until one remembers that firstly, these were embassy staff, precisely the people who meant to be ambassadors for the country (and who can thus be expected to be held to a higher standard than others). Also, it should be remembered that unhappy customers tell more people about their negative experiences than happy customers. This could be referred to as negative word-of-mouth (NWOM). It is defined as interactive communication between customers whereby they depreciate a certain product, service or organisation (Richins, 1984). This is a well-researched occurrence that has been the focus of various studies across the globe. The American Express Survey reported that a person tells nine people about good experiences, but 16 people about poor experiences (American Express, 2012). According to the Sydney Entrepreneur Centre, an unhappy customer tells 11 others about their negative experiences (Customer Thermometer, 2017). The White House Office of Consumer Affairs found that a dissatisfied customer would tell between $9-15$ people about their experience. Moreover, $13 \%$ of disgruntled customers will tell more than 20 people (Customer Thermometer, 2017). Thus, the impact of this handful of unhappy visitors, then, should not be discounted. Word-of-mouth recommendations are a primary source in forming destination image which further emphasises the importance of offering visitors with satisfying experiences (Baloglu \& McCleary, 1999).

Those who indicated that they would be willing to visit SA again were asked to indicate what the main reason would be for visiting the country once more, choosing from business, holiday, or visiting family and friends. Of those, 206 chose only one of the three options, 45 chose any two, and 11 chose all three. From this it can be seen that SA remains popular as a tourist destination, with more than half (51.5\%) of the respondents choosing this as at least one of their main reasons for visiting SA again (Table 3).

Table 3. Main reasons for visiting South Africa again

\begin{tabular}{|l|c|c|}
\hline \multicolumn{1}{|c|}{ Reason } & $\mathbf{N}$ & $\mathbf{\%}$ \\
\hline Business & 110 & $36.1 \%$ \\
\hline Holiday & 157 & $51.5 \%$ \\
\hline Family \& Friends & 62 & $20.3 \%$ \\
\hline
\end{tabular}

Thirty-seven of the respondents who indicated that they would visit SA again also specified the reason why they would return in an open-ended response. Some listed multiple reasons, so that a total of forty-four responses were captured. Education was a major reason, together with those already listed-the importance of the education sector, not only for building up South African society through the upskilling of its populace, but also as a means of bringing in revenue from foreign students, should not be underestimated. During the period January to March 2018 approximately 5\% of international visitors entering South Africa come here for education, training and study purposes. The bulk of these visitors either travel to the Free State (9.3\%), KwaZulu-Natal (7.8\%) or Western Cape (5.9\%) South African Tourism, 2018). 
These students spend about US\$6 ooo on tuition and contribute large amounts to the South African economy as they eat out more often than South African students and travels extensively within South Africa (Cassidy, 2017). They mainly come from the United States, Norway, Germany, Switzerland, Denmark and the Netherlands (Cassidy, 2017). An estimated AU $\$ 32$ billion was generated by foreign students to the Australian economy in 2017. Globally, the United States the majority (19\%) of foreign students followed by the United Kingdom (10\%), Australia and France (6\%), Germany (5\%) and Russia, Canada and Japan (3\%) (University World News, 2018) (Table 4).

Table 4. Written reasons for visiting South Africa again

\begin{tabular}{|l|c|c|}
\hline \multicolumn{1}{|c|}{ Reason to visit again } & N & \% \\
\hline Education & 15 & $34.1 \%$ \\
\hline Friendly people & 3 & $6.8 \%$ \\
\hline Proximity to neighbouring countries & 3 & $6.8 \%$ \\
\hline Shopping & 3 & $6.8 \%$ \\
\hline Wonderful cultural experience & 3 & $6.8 \%$ \\
\hline Business & 2 & $4.5 \%$ \\
\hline Church & 2 & $4.5 \%$ \\
\hline Medical & 2 & $4.5 \%$ \\
\hline Natural beauty & 2 & $4.5 \%$ \\
\hline Am African Blood & 1 & $2.3 \%$ \\
\hline As consultant & 1 & $2.3 \%$ \\
\hline Bird watching & 1 & $2.3 \%$ \\
\hline Conference & 1 & $2.3 \%$ \\
\hline Fun & 1 & $2.3 \%$ \\
\hline Holiday & 1 & $2.3 \%$ \\
\hline Nice place, beautiful country & 1 & $2.3 \%$ \\
\hline Regional meetings & 1 & $2.3 \%$ \\
\hline Who knows & 1 & $2.3 \%$ \\
\hline
\end{tabular}

Again, the reasons for a return visit were grouped as either formal, recreational, or mixed. Figure 3 shows that there were definite differences in the respondents' willingness to visit SA again $(\chi 2=46.38, \mathrm{df}=6, \mathrm{p}<0.0001)$. Interestingly, almost two fifths of respondents who indicated that they had come to SA on this trip for formal reasons (such as business), indicated that they would visit SA again for recreational reasons. This clearly indicates that SA had made a positive impression on them and that they would like to explore the country recreationally (Figure 3). It was also evident that respondent's rating of the overall attractiveness of SA as a tourist destination influenced their willingness to visit SA again $(\chi 2=35.55, \mathrm{df}=12, \mathrm{p}=0.0004)$, with generally those giving the country a better overall rating, being more willing to visit it as a recreational destination in the future (Figure 4).

\section{CONCLUSION}

Given the fact that it is predicted that growth in emerging market and developing economies is projected to plateau in 2018 the economic impact of tourism becomes even more important to a destination such as South Africa (The World Bank, 2018). From the results it is clear that visitors to SA return to visit the destination again. Reasons listed to visit SA again varied from business, formal, recreation and a combination thereof. Some visitors even returned more that five times and still gives the destination as positive rating for its unique attractiveness, especially Cape Town. Fortunately, other cities such as Durban and Johannesburg were included to rate the overall attractiveness of SA as positive with a large majority indicating that they will visit South Africa again. 


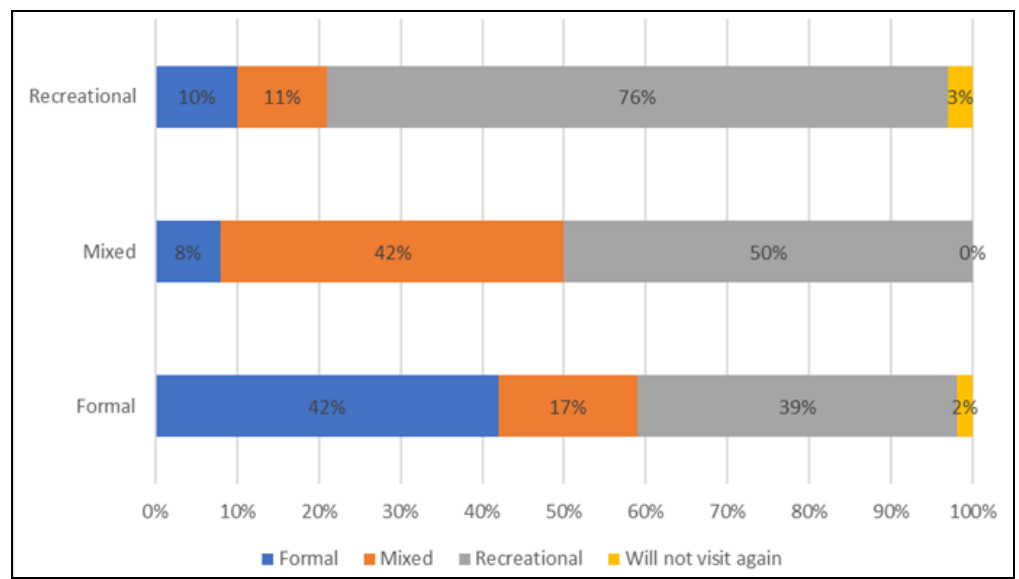

Figure 3. Reason for visit compared to willingness to visit again

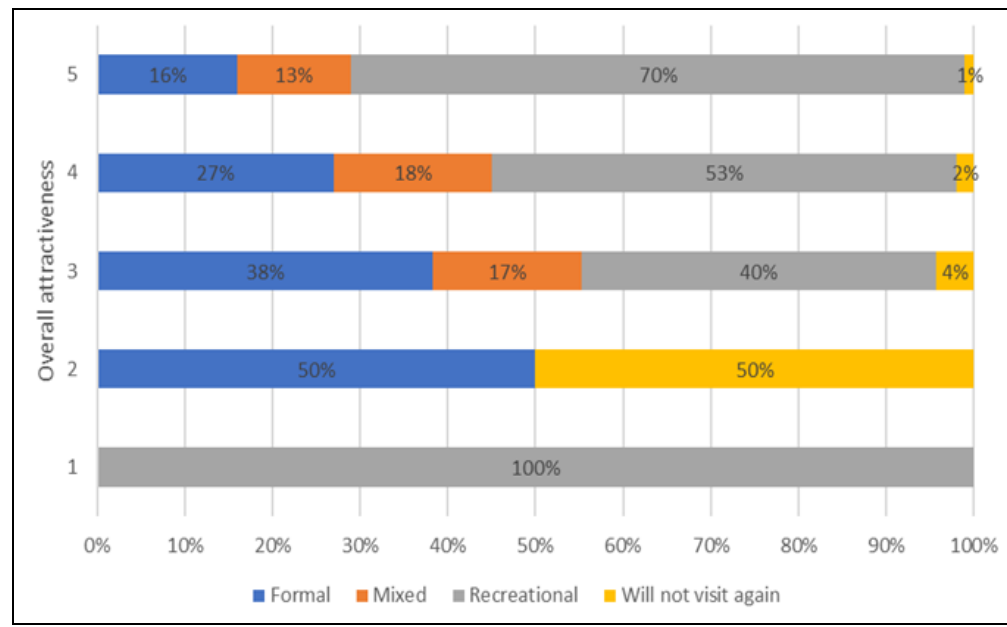

Figure 4. Reason for visit compared to willingness to visit again

Those respondents who visited South Africa for business was the largest majority that furthermore indicated that they would visit SA again for recreational reasons. This clearly indicates that SA had made a positive impression on them and that they would like to explore the country recreationally. Visiting SA for educational reasons was indicated to be important as well as a return visit for recreational purposes. It is suggested that the main tourist cities in SA namely Cape Town, Johannesburg and Durban enhance the marketing of their products offered as a drawcards to SA. To satisfy off the beaten track visitors, emerging markets within SA such as medical tourism, wildlife tourism and religious tourism could also be further investigated to establish the sustainability thereof as a market segment. It is also suggested that the custom tourism products be developed for international visitors entering South Africa to come here for education, training and study purposes as this market may further ehnace the growth of the local tourism market in SA. Lastle, SA should ultimately stive the ensure customer satifaction in a safe and secure environment for visitors to enjoy the best that the destination can offer.

Considering the overall positive rating the SA received as a destination, the marketing slogan 'Alive with possibility' seems to be exactly right, even today. 


\section{REFERENCES}

Baloglu, S. \& McCleary, K.W. (1999). A model of destination image formation. Annals of Tourism Research, 264: 868-897. Beerli, A. \& Martin, J.D. (2004). Factors Influencing Destination Image. Annals of Tourism Research, 31.3: $657-681$. Bramwell, B \& Rawding, L. (1996). Tourism Marketing Images of Industrial Cities. Annals of TourismResearch, 23: $201-221$. Cassidy, S. (2017). Foreign students boost Cape Town economy. IOL https://www.iol.co.za/news/south-africa/ western-cape/foreign-students-boost-cape-town-economy-7378047. (date of reference: 11.01.2017).

Clarke, J. \& Godfrey, K. (2000). The tourism development handbook: A practical approach to planning and marketing. London: Cassell.

Gartner, W.C. (1994). Image Formation Process. Journal of Travel and Tourism Marketing 2.2: 191-216.

Manhas, P.S., Manrai, L.A. \& Manrai, A.K. (2016). Role of tourist destination development in building its brand image: a conceptual model. Journal of Economics, Finance and Administrative Science, 21: 25-29.

Martins, M. (2015). The Tourist Imagery, the Destination Image and the Brand Image. Journal of Tourism and Hospitality Management, 3.2: 1-14.

Maumbe, K. \& Van Wyk, L. (2012). Destination Cape \& Western Cape: Analysis of destination brand awareness, identity and image in the domestic market. Presented at the University of Massachusetts Amherst TTRA International Conference (Amherst, Massachusetts).

Morrison, A.M. (2013). Marketing and Managing Tourism Destinations. Abingdon, Oxon: Routledge.

Richins, M.L. (1984). Word of Mouth Communication as Negative Information. Advances in Consumer Research, 11: 697-702.

Schmallegger, D. \& Carson, D. (2009). Destination Image Projection on Consumer-Generated Content Websites: A Case Study of the Flinders Ranges.” Information Technology and Tourism 11: 111-127.

Schoeman, A. (2016). "SA tourism faces huge African competition." Fin24 https://www.fin24.com/ Economy/sa-tourism-faces-huge-african-competition-20161218-2 (date of reference: 05.08.2016).

*** Airports Company South Africa. (2018). Passenger Statistics 13 August. http://www.airports.co.za/ business/statistics (date of reference: 13.08.2018).

*** All Africa. (2018). South Africa: Brand South Africa On 2017 City Brand Index Findings https://allafrica.com/stories/201803220724.html. (date of reference: 21.03.2018).

*** American Express. (2012). American Express Survey https://about.americanexpress.com/news/pr /2012/gcsb.aspx. (date of reference: 12.08.2012).

*** Brand South Africa Trust. (2018). Annual Performance Plan 2018/2019.

*** Business Dictionary. (2018). Definition of development http://www.businessdictionary.com/ definition/development.html. (date of reference: 15.08.2018).

*** Cape Town Tourism. (2018). Cape Town Accolades and Awards http://www.capetown.travel/trademedia/tm-news/cape-town-accolades/cape-town-accolades-and-awards/(date of reference: 13.08.2018).

*** Customer Thermometer. (2017). CSAT Stat of the Month: An Unhappy Customer Tells https://www. customerthermometer.com/customer-satisfaction/csat-stat-of-the-month/ (13.08.2017).

*** South Africa. (2018). Popular South African Attractions http://country.southafrica.net/country/us/en/ top10/entry/top-10-attractions-enus (date of reference: 16.08.2018).

South African Market Insights. (2017). Tourism Statistics for South Africa https://www.southafricanmi. com/tourism.html. (date of reference: 07.08.2017).

*** South African Tourism. (2017). International Tourism Report: 2017 Quarter 3Report. https://sat-backendlive.azurewebsites.net/media/207822/q3-2017-consolidated-tourism-report10072018.pdf?downloadId=223396 (date of reference: 04.06.2017).

*** South African Tourism. (2017). South African Tourism Annual Report 2016/2017. https://sat-backendlive.azurewebsites.net/media/207056/sat-annual-report2017_v23_14062018.pdf?downloadId=231808 (date of reference: 03.04.2017).

*** South African Tourism. (2018). About South African Tourism https://www.southafrica.net/gl/en/ corporate/page/about-south-african-tourism (date of reference: 07.08.2018).

*** South African Tourism. (2018). International Tourism Report: 2018 Quarter 1 Report. https://sat-backendlive.azurewebsites.net/media/208773/quarter-1-2018-travel-patterns-in-south-africa.pdf?downloadId $=238074$ (15.08.2018).

*** Statistics South Africa. (2018). How important is tourism to the South African economy? http://www. statssa.gov.za/?p=11030 (date of reference: 07.08.2018).

*** The World Bank. (2018). Global Economic Prospects http://www.worldbank.org/en/publication/globaleconomic-prospects (16.08.2018).

*** University World News. (2018). Foreign students' economic contribution soars by 22\% http://www. universityworldnews.com/article.php?story=20180410110537639 (date of reference: 10.04.2018).

*** World Travel \& Tourism Council. (2017). Travel \& Tourism Economic Impact 2017 South Africa.

Submitted:

22.10.2018
Revised:

18.02.2019
Accepted and published online

20.02.2019 